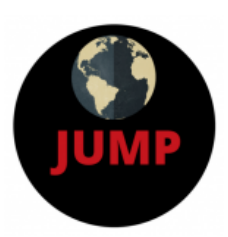

\title{
OJED
}

ISSN: 2574-3465 Print/ ISSN: 2574-3481 Online

Volume 4, Issue 2 (2020), pp. 302-305

(C) Journal of Underrepresented and Minority Progress

http://ojed.org/jump

\section{Teaching Educational Leadership in Muslim Countries: Theoretical, Historical and Cultural Foundations}

Samier, E. A., \& ElKaleh, E. S. (Ed.). (2019c). Springer. ISBN: 978-98113-6817-2

Reviewed By: Megan X. Schutte, Community College of Baltimore County, USA

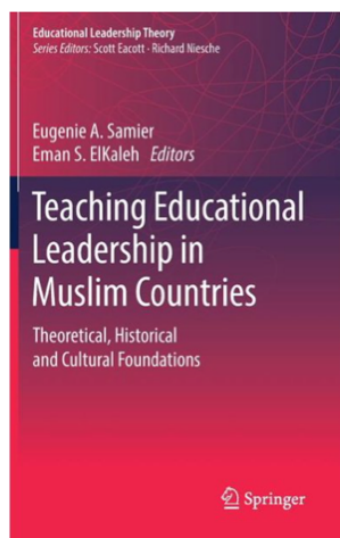

Samier and ElKaleh's (2019c) edited book titled Teaching Educational Leadership in Muslim Countries: Theoretical, Historical and Cultural Foundations is part of the Educational Leadership Theory series, which aims to address works on educational leadership in an inventive and thoughtprovoking way. Samier and ElKaleh (2019c) fulfill this mandate of "dialogue and debate" (Eacott \& Niesche, 2019, p. vi) in their presentation of various perspectives regarding teaching educational administration and leadership in Muslim countries.

As the authors state in the Preface, while higher education is expanding in the Middle East, many educational leaders in Islamic nations continue to use Western leadership ideals and methods of teaching, which often are not compatible with Islam (Samier \& ElKaleh, 2019c). As such, the purpose of this book is to address the dearth of literature on educational leadership from a Muslim context, not simply a Westernized version of what is taught in Muslim countries. The book proposes "alternative approaches" as well as showing that Islamic traditions can work well in the field as long as appropriate modifications are considered (Samier \& ElKaleh, 2019c, p. x).

While the audience for this book is not explicitly stated, the dichotomous backgrounds of the editors' hint at who they are attempting to 
reach. One is a Western-based scholar with experience in international and comparative studies and the other is a Muslim-country-born-and-raised scholar with a background in Western management and leadership studies. The merging of these perspectives - with a focus on the work as "a human and humane pursuit" (Samier \& ElKaleh, 2019c, p. ix)—works remarkably well. The authors walk the fine line between providing context and explanation without being condescending and overly simplistic. Much of the writing seems geared to a Western audience (e.g., Education in the Islamic Traditions and Administration and Leadership in the Islamic Traditions, two sections in the Editors' Introduction that help orient the reader), but they also provide an acknowledgment of the heterogeneity of Islamic tradition (i.e., "there are many differences among Muslim states and communities through political and cultural practices" [Samier \& ElKaleh, 2019c, p. 3]). This follows their argument regarding the lack of research on educational leadership in Muslim countries. Still further, Part III focuses on case studies in three Middle Eastern nations which would appeal to individuals working in those countries. In this way, Samier and ElKaleh (2019c) manage to edit a text that appeals to both Westerners with an interest in academic leadership in Muslim countries and those actually living the experience.

The organization of the book is straight-forward and logical. Each chapter begins with an abstract, which is helpful for a reader who is looking for information on a specific subject or country. Chapter 1 , written by the editors, helps to orient the reader to the subject matter and discusses the organizational structure of the book (Samier \& ElKaleh, 2019a). This chapter - more than the others - has a universal appeal as it provides a list of sources the reader might be interested in, context of the Arab world's place in higher education today, and education's and leadership's roles in Islam.

Following the introductory chapter, Samier and ElKaleh's (2019c) text is divided into three sections, each containing three chapters. Part I, "Foundational Theories and Models," focuses on the development of ideas supporting educational leadership and leadership curriculum in Arab countries. After the orienting Chapter 1, Chapter 2, written by one of the editors, argues that basic humanistic values are culturally universal while comparing Islamic and Western humanism (Samier, 2019). Next, Chapter 3, written by the other editor, presents a critical theory model that attempts to balance Islamic cultural values with Western-focused scholarship (ElKaleh, 2019), as well as the author's real-life experience implementing the model. Part 1 ends with Chapter 4, which aims to re-center the leadership field to focus on pedagogy rather than management (Harold \& Stephenson, 2019) 
while allowing students in the United Arab Emirates to integrate Western viewpoints into their own, culturally-relevant leadership practices.

Part II delves into "Current Controversies and Challenges." The section begins with Chapter 5, a look at the balance between universal research challenges and local cultural sensitivities (Karami-Akkary \& Hammad, 2019). Chapter 6 is a response to the argument that Islam and modernization are incompatible. Conversely, the authors argue that contradictions do not exist and that using Islamic principles and Shura (the concept of mutual consultation) can help Muslim countries modernize in their own way (Samier \& ElKaleh, 2019b). Chapter 7 embodies the traditional structure of a research article, ultimately using the Qatar National Vision 2030 as a model for diversifying the economy in a manner that incorporates ethical and moral ideals into one's work (Tok \& D'Alessandro, 2019).

Finally, Part III uses individual case studies from Turkey (Chapter 8), Iran (Chapter 9), and Saudi Arabia (Chapter 10). Each chapter begins with some background/context and then delves into more current relevance. These three chapters are very specific, and may only be interesting to those with experience in the particular countries.

Although the book is ostensibly centered on "Muslim" countries, the content has a decidedly Middle Eastern focus. "Arab" and "Muslim" are, at times, used interchangeably. This is, of course, problematic in that it ignores all south east Asian nations that are predominantly Muslim. This might alienate some readers. Part III-the country case studies - too might lack appeal for all readers, though in a less off-putting way than the aforementioned criticism. The information in these chapters is often very specific to the extent that a casual reader might not fully grasp the content.

Overall, though, this book provides excellent information for both a Western audience interested in educational leadership in the Middle East and Middle Eastern practitioners interested in specifics about their field, its challenges, and its future. Samier and ElKaleh provide general, foundational, as well as contextual information for any reader who picks up Teaching Educational Leadership in Muslim Countries: Theoretical, Historical and Cultural Foundations.

\section{REFERENCES}

Eacott, S., \& Niesche, R. (2019). Series editors' foreword. In E. A. Samier \& E. S. ElKaleh (Eds.), Teaching educational leadership in Muslim countries: Theoretical, historical and cultural foundations (pp. v-vii). Springer.

ElKaleh, E. S. (2019). A critical approach to developing culturally relevant leadership curricula for Muslim students. In E. A. Samier \& E. S. ElKaleh (Eds.), Teaching educational leadership in Muslim countries: Theoretical, historical and cultural foundations (pp. 39-53). Springer. 
Harold, B., \& Stephenson, L. (2019). Leadership development in the UAE: Critical perspectives on intercultural pedagogies in a graduate education programme. In E. A. Samier \& E. S. ElKaleh (Eds.), Teaching educational leadership in Muslim countries: Theoretical, historical and cultural foundations (pp. 5574). Springer.

Karami-Akkary, R., \& Hammad, W. (2019). The knowledge base on educational leadership and management in Arab countries: Its current state and its implications for leadership development. In E. A. Samier \& E. S. ElKaleh (Eds.), Teaching educational leadership in Muslim countries: Theoretical, historical and cultural foundations (pp. 77-92). Springer.

Samier, E. A. (2019). The humanistic roots of Islamic administration and leadership for education: Philosophical foundations for intercultural and transcultural teaching. In E. A. Samier \& E. S. ElKaleh (Eds.), Teaching educational leadership in Muslim countries: Theoretical, historical and cultural foundations (pp. 23-38). Springer.

Samier, E. A., \& ElKaleh, E. S. (2019a). Editors' introduction: An overview of the educational administration and leadership curriculum: Traditions of Islamic educational administration and leadership in higher education. In E. A. Samier \& E. S. ElKaleh (Eds.), Teaching educational leadership in Muslim countries: Theoretical, historical and cultural foundations (pp. 1-20). Springer.

Samier, E. A., \& ElKaleh, E. S. (2019b). Educational administration and leadership curricula for modern nation-building in Muslim countries: Modernisation, national identity and the preservation of values and culture. In E. A. Samier \& E. S. ElKaleh (Eds.), Teaching educational leadership in Muslim countries: Theoretical, historical and cultural foundations (pp. 93-111). Springer.

Samier, E. A., \& ElKaleh, E. S. (Eds.). (2019c). Teaching educational leadership in Muslim countries: Theoretical, historical and cultural foundations. Springer.

Tok, M. E., D’Alessandro, C. (2019). Locality, leadership and pedagogies for entrepreneurship education. In E. A. Samier \& E. S. ElKaleh (Eds.), Teaching educational leadership in Muslim countries: Theoretical, historical and cultural foundations (pp. 113-132). Springer.

MEGAN X. SCHUTTE is an Associate Professor of English and the Director of the Writing and Literacy Centers at the Community College of Baltimore County. She is also a doctoral candidate in the Higher Education Administration program at Morgan State University. When she actually has time to be a normal human, she loves to travel and watch soccer (often together), design her own high heels, and play with her adorable nephews. Email: mschutte@ccbcmd.edu

Manuscript submitted: March 5, 2020

Manuscript revised: June 14, 2020

Accepted for publication: August 17, 2020 